DOI: https://doi.org/10.15688/jvolsu5.2016.4.21

UDC 347.918(075)

LBC 67.410.12я73

\title{
ANALYSIS OF WRIT PROCEEDINGS IN THE ARBITRATION PROCESS
}

\author{
Yanina Ya. Kayl \\ Russian Presidential Academy of National Economy and Public Administration (Volgograd Branch), \\ Volgograd, Russian Federation
}

Introduction. Procedural legislation has been changed dynamically. For the first time a new type of procedure writ proceedings - is introduced in the APC of the Russian Federation. The purpose of research is to reveal the rules of treatment, consideration of the issuance of the writ and to perform arbitration practice. Methods. The author applied the methods of scientific knowledge, including basic methods of system analysis and comparative-legal analysis. Results. It is proved that not all categories of cases apply for the issuance of the writ, the court observed the order and terms of their consideration, arbitration practice on this category of cases varied on the basis of application for issuance of a writ, and the grounds used by the court for return of applications on the issuance of the writ. Conclusions. It was found that intervening changes in the APC had the desired effect, and the number of applications for restraining orders is constantly growing, that testifies to the effectiveness of the new adopted type of proceedings.

Key words: writ, determination, arbitration court, terms, return grounds, funds recovery.

УДК $347.918(075)$

ББК 67.410 .12 я73

\section{АНАЛИЗ ПРИКАЗНОГО ПРОИЗВОДСТВА В АРБИТРАЖНОМ ПРОЦЕССЕ}

\author{
Янина Яковлевна Кайль
}

Российская академия народного хозяйства и государственной службы при Президенте РФ

(Волгоградский филиал), г. Волгоград, Российская Федерация

Введение: процессуальное законодательство динамично изменяется, впервые в АПК РФ внесен новый вид судопроизводства - приказное производство. Цель исследования - раскрыть правила обращения, рассмотрения заявлений о выдаче судебного приказа и проанализировать арбитражную практику. Методы: применены в совокупности методы научного познания, среди которых основные - методы системности, анализа и сравнительно-правовой. Результаты: обосновано, что не по всем категориям дел обращаются с заявлением о выдаче судебного приказа, судом соблюдаются порядок и сроки его рассмотрения, арбитражная практика по данной категории дел разнообразна как по основаниям обращения за выдачей судебного приказа, так и по основаниям, используемым судом для возврата заявлений о выдаче судебного приказа. Выводы: установлено, что вступившие изменения в АПК РФ принесли желаемый результат и количество обращений за выдачей судебного приказа постоянно растет, что свидетельствует об эффективности принятого нового вида судопроизводства.

Ключевые слова: судебный приказ, определение, арбитражный суд, сроки, основания возврата, взыскание денежных средств.

\section{В ведение}

Участники процесса часто сталкиваются с процедурами, затягивающими судебный процесс и рассмотрение дела. Реформы граж- данского и арбитражного процессуального законодательства, происходящие в последнее время, связаны с упрощением и ускорением процесса в целях восстановления нарушенных или оспариваемых прав граждан и юридичес- 
ких лиц. Как справедливо замечает П.М. Филиппов, объединение Верховного суда РФ и Высшего арбитражного суда РФ должно привести к единообразию судебной политики в стране [16].

В процессуальном законодательстве предусмотрено несколько способов ускорить или упростить рассмотрение дела [3]. Мы рассмотрим один из таких способов, впервые введенный 1 июня 2016 г. в арбитражный процесс: приказное производство.

\section{Порядок обращения с заявлением в арбитражный суд для выдачи судебного приказа}

В статье 229.1 АПК РФ дается понятие судебного приказа [1]. Судебный приказ - судебный акт, вынесенный судьей единолично на основании заявления о взыскании денежных сумм по требованиям взыскателя, предусмотренным ст. 229.2 АПК РФ. В этом определении не указываются предельные суммы требований по денежным взысканиям.

В соответствии со ст. 229.2 АПК РФ судебный приказ в арбитражном суде выдается по трем категориям дел.

Если рассматривать судебную практику о выдаче судебного приказа по п. 1 ст. 292.2 АПК, можно привести в пример следующее дело, в котором суд указал на отсутствие оснований по заявлению в выдаче судебного приказа, мотивируя это тем, что в материалах дела отсутствуют документы, подтверждающие направление ответчику претензии об оплате суммы пени, соответственно нет оснований считать, что документы, приложенные к заявлению о выдаче судебного приказа, свидетельствуют о признании ответчиком задолженности в полном объеме [8].

В общедоступной базе судебных актов обращений в суд с требованиями по п. 2 ст. 229.2 АПК РФ не зафиксировано. Объяснить такое отсутствие заявлений о выдаче судебных приказов можно тем, что для векселя сумма 400000 рублей в арбитражном суде является очень незначительной, в связи с этим данное основание не является востребованным. Участники процесса с данными требованиями обращаются в исковом порядке, о чем свидетельствует арбитражная практика.
Если рассматривать обращения по п. 3 ст. 229.2 АПК РФ, то можно привести следующее показательное судебное дело о возврате искового заявления, поскольку данное дело должно рассматриваться по правилам приказного производства. Истцом заявлено требование к ответчику о взыскании задолженности по обязательным платежам в размере 14 490,47 руб., то есть в размере, не превышающем сто тысяч рублей. Судья в определении о возврате искового заявления указал, что требования подлежат рассмотрению в порядке приказного производства [9].

В арбитражный суд заявление о выдаче судебного приказа в соответствии со ст. 229.3 оформляется в письменном виде и направляется в суд как на бумажном носителе, так и в электронном виде, в том числе в форме электронного документа, подписанного электронной подписью. В соответствии с п. 5 параграфа 1 Временного порядка подачи документов в арбитражные суды Российской Федерации в электронном виде [2] в случае, если при обращении в суд документы были представлены в электронном виде, они не возвращаются заявителю.

В части 2 ст. 229.3 АПК РФ закреплены требования, предъявляемые к заявлению о выдаче судебного приказа. Следует обратить внимание на то, что необходимо извещать должника о поданном заявлении, поскольку в ч. 4 ст. 229.3 АПК РФ к заявлению о выдаче судебного приказа прилагается уведомление о вручении или иные документы, подтверждающие направление взыскателем должнику копии заявления о выдаче судебного приказа.

\section{Основания для возврата заявления о выдаче судебного приказа}

В статье 229.4 АПК РФ указаны только основания для возвращения заявления о выдаче судебного приказа, поскольку АПК РФ не знает института отказа в приеме как искового заявления, так и иного заявления.

Таким образом, основаниями для возвращения заявления о выдаче судебного приказа выступают следующие:

1. В случае нарушения требований к форме и содержанию заявления о выдаче судебного приказа, установленных ст. 229.3 АПК 
РФ. Нарушение формы суд усматривает, если при подаче заявления не были указаны необходимые реквизиты, а именно: идентификационный номер налогоплательщика, основной государственный регистрационный номер, банковские и другие необходимые реквизиты взыскателя и должника в электронном виде [5], если в материалах дела отсутствуют документы, подтверждающие факт бесспорного признания ответчиком заявленного требования [10], если в приложении к заявлению о выдаче судебного приказа нет копии заявления о вручении его должнику [6], если заявлено ходатайство об отсрочке, рассрочке, уменьшении размера госпошлины при обращении в арбитражный суд с заявлением о выдаче судебного приказа, поскольку законом не предусмотрена такая возможность для данного вида судопроизводства [14], если к заявлению заявителем не приложены доказательства надлежащего направления требования об уплате недоимки в адрес ответчика, в доказательство соблюдения досудебного порядка урегулирования спора заявитель не представил почтовой квитанции в подтверждение отправки требований в адрес суда, в подтверждение доводов к заявлению приложены ксерокопии документов, из которых не усматривается, кем заверены соответствующие копии документов [11].

2. Дело неподсудно данному арбитражному суду. Например, Арбитражный суд Брянской области возвратил заявление, так как стороны, заключая договор, пришли к соглашению об установлении договорной подсудности в Арбитражном суде г. Москвы, а не по общему правилу территориальной подсудности - по месту нахождения должника [4].

3. До вынесения определения о принятии заявления о выдаче судебного приказа к производству от взыскателя поступило ходатайство о возвращении этого заявления.

Нередко взыскатель сам подает заявление о возврате ранее поданного приказа, и суд своим определением его возвращает [12].

4. Заявлено требование, не предусмотренное ст. 229.2 АПК РФ.

Например, из действующего законодательства следует обязанность заявителя в деле о взыскании обязательных платежей и санкций изложить в заявлении сведения о на- правлении требования об уплате налогов (штрафов) и приложить к заявлению документ, подтверждающий направление этого требования должнику [13].

5. Место жительства или место нахождения должника находится вне пределов Российской Федерации.

6. Из заявления о выдаче судебного приказа и приложенных документов усматривается наличие спора о праве.

Например, суд усмотрел спор о праве и отказал выдать судебный приказ, поскольку заявитель ходатайствовал о восстановлении пропущенного процессуального срока для взыскания суммы в судебном порядке, ссылаясь на то, что задолженность была обнаружена только в 2016 г., а такие требования не могут быть включены в судебный приказ [15].

О возвращении заявления о выдаче судебного приказа арбитражный суд выносит определение в течение трех дней со дня поступления этого заявления в суд, которое может быть обжаловано в апелляционном порядке в течение месяца с даты его принятия.

\section{Процедура приказного производства в арбитражном процессе}

Порядок приказного производства в арбитражном суде регулируется ст. 229.5 АПК РФ. Заявление о выдаче судебного приказа подается по общим правилам родовой и территориальной подсудности. По родовой подсудности судебный приказ подается в арбитражный суд соответствующего субъекта РФ по общему правилу территориальной подсудности - по месту нахождения должника.

Судебный приказ по существу заявленного требования выносится в течение десяти дней со дня поступления заявления о вынесении судебного приказа в арбитражный суд без проведения судебного разбирательства и вызова сторон.

Суд исследует изложенные в направленном взыскателем заявлении о выдаче судебного приказа и приложенных к нему документах сведения в обоснование позиции данного лица и выносит судебный приказ на основании представленных письменных доказательств.

В ходе приказного производства не используются правила о применении обеспечи- 
тельных мер, нет института оставления без движения, поданного заявления о выдаче судебного приказа, должником не может быть подан встречный иск, нет стадии подготовки дела к судебному разбирательству и самого судебного разбирательства, по данной категории дел стороны не могут заключить мировое соглашение, сроки рассмотрения дела не могут быть приостановлены, невозможно прекратить производство по делу.

Общим правилом является требование о выполнении судебного приказа в форме электронного документа, подписанного усиленной квалифицированной электронной подписью, а также на бумажном носителе в двух экземплярах. Экземпляры судебного приказа, выполненные на бумажном носителе, составляются на специальном бланке и подписываются судьей.

Копия судебного приказа на бумажном носителе в пятидневный срок со дня его вынесения высылается должнику, который в течение десяти дней со дня ее получения вправе представить возражения относительно порядка исполнения судебного приказа.

Если от должника в десятидневный срок поступят возражения относительно его исполнения, то судья обязан отменить ранее вынесенный судебный приказ [7].

Судебный приказ вступает в законную силу по истечении срока для представления возражений относительно исполнения судебного приказа и может быть обжалован в арбитражный суд, в кассационную инстанцию.

Копии определения суда, судебного приказа направляются взыскателю и должнику в срок, не превышающий пяти дней со дня его вынесения. Судебный приказ или определение об его отмене должны быть размещены на официальном сайте арбитражного суда в информационно-телекоммуникационной сети «Интернет» не позднее следующего дня после дня его вынесения. Арбитражные суды, в отличие от судов общей юрисдикции, несмотря на схожую компетенцию, размещают акты, вынесенные в приказном порядке, без обезличивания персональных данных.

\section{Выводы}

Изучив судебную практику Арбитражного суда Волгоградской области, можно с уве- ренностью констатировать, что вступившие изменения в АПК РФ принесли желаемый результат и количество обращений за выдачей судебного приказа постоянно растет, заявления же об отмене судебного приказа поступили в единичном количестве, что свидетельствует об эффективности принятого нового вида судопроизводства - приказного производства в арбитражном суде.

\section{СПИСОК ЛИТЕРАТУРЫ}

1. Арбитражный процессуальный кодекс Российской Федерации от 24 июля 2002 г. № 95-Ф3 : (ред. от 23 июня 2016 г.) : (с изм. и доп., вступ. в силу c 1 сент. 2016 г.). - Доступ из справ.-правовой системы «КонсультантПлюс».

2. Временный порядок подачи документов в арбитражные суды Российской Федерации в электронном виде : (утв. Приказом ВАС РФ от 12 янв. 2011 г. № 1). - Доступ из справ.-правовой системы «КонсультантПлюс».

3. Кайль, Я. Я. Упрощение и ускорение рассмотрения дела в условиях реформирования гражданского процессуального законодательства / Я. Я. Кайль // Третьи Юридические чтения : сб. материалов Всерос. науч.-практ. конф., г. Сыктывкар, 26-27 нояб. 2015 г. - Сыктывкар : Изд-во СГУ им. Питирима Сорокина, 2016. - С. 153-158.

4. Определение Арбитражного суда Брянской области от 18 окт. 2016 г. о возвращении заявления о выдаче судебного приказа по делу № А09-15296/ 2016. - Электрон. текстовые дан. - Режим доступа: http://sudact.ru/arbitral/doc/Ts7je5aCpwJq/. - Загл. c экрана.

5. Определение Арбитражного суда Волгоградской области о возвращении заявления о выдаче судебного приказа от 9 сент. 2016 г. по делу № A12-51960/2016. - Электрон. текстовые дан. Режим доступа: http://sudact.ru/arbitral/doc/ IbewNCUHZw1h/. - Загл. с экрана.

6. Определение Арбитражного суда Волгоградской области о возвращении заявления о выдаче судебного приказа от 31 авг. 2016 г. по делу № A12-50484/2016. - Электрон. текстовые дан. Режим доступа: http://sudact.ru/arbitral/doc/ TGdKhvj0B9la/. - Загл. с экрана.

7. Определение Арбитражного суда Волгоградской области от 5 сент. 2016 г. об отмене судебного приказа по делу № A12-44715/2016. - Электрон. текстовые дан. - Режим доступа: http://sudact.ru/ arbitral/doc/P2dVtgqjwtHo/. - Загл. с экрана.

8. Определение Арбитражного суда Волгоградской области от 8 сент. 2016 г. по делу № А12- 
51959/2016. - Электрон. текстовые дан. - Режим доступа: http://sudact.ru/arbitral/doc/Xvef510K5MYx/. Загл. с экрана.

9. Определение Арбитражного суда Волгоградской области от 7 сент. 2016 г. по делу № А12-51769/ 2016. - Электрон. текстовые дан. - Режим доступа: http://sudact.ru/arbitral/doc/wKYVNKxJV6ZW . -Загл. с экрана.

10. Определение Арбитражного суда Волгоградской области от 5 сент. 2016 г. по делу № А1251102/2016. - Электрон. текстовые дан. - Режим доступа: http://sudact.ru/arbitral/doc/GxpqWyb00hLl/. Загл. с экрана.

11. Определение Арбитражного суда Волгоградской области от 13 июля 2016 г. по делу № А1238530/2016. - Электрон. текстовые дан. - Режим доступа: http://sudact.ru/arbitral/doc/frIvcv5iLWLQ/. Загл. с экрана.

12. Определение Арбитражного суда Волгоградской области от 5 сент. 2016 г. по делу № А1248707/2016. - Электрон. текстовые дан. - Режим доступа: http://sudact.ru/arbitral/doc/0vUR5quygc10/.Загл. с экрана.

13. Определение Арбитражного суда Волгоградской области от 26 июля 2016 г. по делу № А1241327/2016. - Электрон. текстовые дан. - Режим доступа: http://sudact.ru/arbitral/doc/3za6qka07Klw/. Загл. с экрана.

14. Определение Арбитражного суда Республики Хакасии от 20 сент. 2016 г. о возвращении заявления о выдаче судебного приказа по делу № А 74-11444/ 2016. - Электрон. текстовые дан. - Режим доступа: http://sudact.ru/arbitral/doc/orNeTJUj2MoW. - Загл. с экрана.

15. Определение Арбитражного суда Республики Хакасии от 19 сент. 2016 г. о возвращении заявления о выдаче судебного приказа по делу № А7411446/2016. - Электрон. текстовые дан. - Режим доступа: http://sudact.ru/arbitral/doc/eny7Ix3p93Yu/. Загл. с экрана.

16. Филиппов, П. М. Судебная реформа и ее движение / П. М. Филиппов // Вестник Волгоградского государственного университета. Серия 5, Юриспруденция. - 2015. - № 4 (29). - С. 123-129.

\section{REFERENCES}

1. Arbitrazhnyy protsessualnyy kodeks Rossiyskoy Federatsii ot 24 iyulya 2002 g. № 95-FZ: (red. ot 23 iyunya 2016 g.): (s izm. i dop., vstup. v silu s 1 sent. 2016 g.) [Arbitration Procedure Code of the Russian Federation of July 24, 2002 no. 95-FL (ed. of June 23, 2016): (with amend. and add., entered into force on September January 2016.)]. Access from reference legal system "KonsultantPlyus".
2. Vremennyy poryadok podachi dokumentov $v$ arbitrazhnye sudy Rossiyskoy Federatsii v elektronnom vide: (utv. Prikazom VAS RF ot 12 yanv. 2011 g. № 1) [Temporal Procedure for Filing Documents in Russian Arbitration Courts in Electronic Form (Approved by Order of the Supreme Arbitration Court of the Russian Federation of January 12, 2011 no. 1)]. Access from reference legal system "KonsultantPlyus".

3. Kayl Ya.Ya. Uproshchenie i uskorenie rassmotreniya dela $\mathrm{v}$ usloviyakh reformirovaniya grazhdanskogo protsessualnogo zakonodatelstva [Simplification and acceleration of the proceedings in the conditions of reforming of civil procedural law]. Tretyi Yuridicheskie chteniya: sb. materialov Vseros. nauch.-prakt. konf., g. Syktyvkar, 2627 noyab. 2015 g. [Third Law Readings: Collected Materials of All-Russian Scientific-Practical Conference, Syktyvkar, November 26-27, 2015]. Syktyvkar, Izd-vo SGU im. Pitirima Sorokina, 2016, pp. 153-158.

4. Opredelenie Arbitrazhnogo suda Bryanskoy oblasti ot 18 okt. 2016 g. o vozvrashchenii zayavleniya o vydache sudebnogo prikaza po delu № A09-15296/2016 [Determination of the Arbitration Court of Bryansk region of October 18, 2016 on the return of the application for issuing a writ on the case no. A09-15296/2016].

5. Opredelenie Arbitrazhnogo suda Volgogradskoy oblasti o vozvrashchenii zayavleniya o vydache sudebnogo prikaza ot 9 sent. 2016 g. po delu № A12-51960/2016 [Determination of the Arbitration Court of the Volgograd region of the return of the application for a writ of 9 September. 2016 on the case no. A12-51960/2016].

6. Opredelenie Arbitrazhnogo suda Volgogradskoy oblasti o vozvrashchenii zayavleniya o vydache sudebnogo prikaza ot $31 \mathrm{avg} .2016 \mathrm{~g}$. po delu № A12-50484/2016 [Determination of the Arbitration Court of the Volgograd region of the return of the application for issuing a writ on the case no. A1250484/2016].

7. Opredelenie Arbitrazhnogo suda Volgogradskoy oblasti ot 5 sent. 2016 g. ob otmene sudebnogo prikaza po delu № A12-44715/2016 [Determination of the Arbitration Court of the Volgograd Region of September 5, 2016 on the abolition of the writ on the case no. A12-44715/2016].

8. Opredelenie Arbitrazhnogo suda Volgogradskoy oblasti ot 8 sent. 2016 g. po delu № A1251959/2016 [Determination of the Arbitration Court of the Volgograd region on the case no. A12-51959/2016].

9. Opredelenie Arbitrazhnogo suda Volgogradskoy oblasti ot 7 sent. 2016 g. po delu № A12-51769/2016 [Determination of the Arbitration Court of the Volgograd region of September 7, 2016 on the case no. A12-51769/2016]. 
Я.Я. Кайль. Анализ приказного производства в арбитражном процессе

10. Opredelenie Arbitrazhnogo suda Volgogradskoy oblasti ot 5 sent. 2016 g. po delu № A 12-51102/2016 [Determination of the Arbitration Court of the Volgograd Region of September 5, 2016 on the case no. A12-51102/2016].

11. Opredelenie Arbitrazhnogo suda Volgogradskoy oblasti ot 13 iyulya $2016 \mathrm{~g}$. po delu № A12-38530/2016 [Determination of the Arbitration Court of the Volgograd region of July 13, 2016 on the caseno. A12-38530/2016].

12. Opredelenie Arbitrazhnogo suda Volgogradskoy oblasti ot 5 sent. 2016 g. po delu № A12-48707/2016 [Determination of the Arbitration Court of the Volgograd Region of September 5, 2016 on the case no. A12-48707/2016].

13. Opredelenie Arbitrazhnogo suda Volgogradskoy oblasti ot 26 iyulya 2016 g. po delu № A12-41327/2016 [Determination of the Arbitration Court of the Volgograd region of July 26, 2016 on the case no. A12-41327 / 2016].
14. Opredelenie Arbitrazhnogo suda Respubliki Khakasii ot 20 sent. 2016 g. o vozvrashchenii zayavleniya o vydache sudebnogo prikaza po delu № A74-11444/2016 [Determination of the Arbitration Court of the Republic of Khakassia of September 20, 2016 on the return of the application for issuing a writ on the case no. A74-11444/2016].

15. Opredelenie Arbitrazhnogo suda Respubliki Khakasii ot 19 sent. 2016 g. o vozvrashchenii zayavleniya o vydache sudebnogo prikaza po delu № A74-11446/2016 [Determination of the Arbitration Court of the Republic of Khakassia of September 19, 2016 on the return of the application for issuing a writ on the case no. A74-11446/2016].

16. Filippov P.M. Sudebnaya reforma i ee dvizhenie [Judicial reform and its movement]. Vestnik Volgogradskogo gosudarstvennogo universiteta. Seriya 5, Yurisprudentsiya [Science Journal of Volgograd State University. Jurisprudence], 2015, no. 4 (29), pp. 123-129.

\section{Information About the Author}

Yanina Ya. Kayl, Candidate of Juridical Sciences, Associate Professor, Department of Civil Legal Disciplines, Russian Presidential Academy of National Economy and Public Administration (Volgograd Branch), Gagarina St., 8, 400131 Volgograd, Russian Federation, Yanika@bk.ru.

\section{Информация об авторе}

Янина Яковлевна Кайль, кандидат юридических наук, доцент кафедры гражданско-правовых дисциплин, Российская академия народного хозяйства и государственной службы при Президенте РФ (Волгоградский филиал), ул. Гагарина, 8, 400131 г. Волгоград, Российская Федерация, Yanika@bk.ru. 